\title{
USO DA ENXERTIA NA PRODUÇÃO DE MUDAS DE MELOEIRO
}

\section{GRAFTING IN MELON SEEDLINGS PRODUCTION}

\author{
Marcos Paulo dos Santos ${ }^{1 *}$, Leonnardo Cruvinel Furquim² ${ }^{2}$ Nívea Patrícia Ribeiro Reges ${ }^{3}$, Abadia dos \\ Reis Nascimento ${ }^{4}$
1*Doutorando em Agronomia pela Universidade Federal de Goiás -marcospaulo_agronomo@hotmail.com 2Instituto de Ensino Superior de Rio Verde (IESRIVER) e doutorando em Agronomia na UFG - leonnardolp@hotmail.com;
32Engenheira Agrônoma - niveapaty@hotmail.com;
${ }^{4}$ Professora Dra. da Universidade Federal de Goiás - abadiadosreis@ufg.br

\begin{abstract}
Resumo: A enxertia surge no cenário de produção de hortaliças como estratégia de escape a condições adversas oriundas do cultivo contínuo destas plantas em uma mesma área durante praticamente todo o ano. A escolha dos materiais a serem usados como enxerto e porta-enxertos aliada ao tipo de enxertia definem o sucesso da técnica na produção de mudas comerciais. Dentre as vantagens proporcionadas pela enxertia destacam-se a possibilidade de aumento da resistência das plantas à patógenos de solo, salinidade, déficit hídrico e ainda incrementos na produtividade e qualidade de frutos. Para o melão, o maior gargalo no emprego da enxertia é a obtenção de porta-enxertos que se adaptem ao meio ambiente, não interfiram negativamente na qualidade dos frutos e mantenham a resistência às doenças por longo período de tempo. As causas de incompatibilidade na enxertia do meloeiro ainda não estão bem esclarecidas e respostas incompatíveis podem surgir mesmo após o transplantio. O incentivo ao rastreamento de combinações de porta-enxerto/enxerto para o melão figura como meio potencial para superar estas limitações, visto que a gama de porta-enxertos comercias é limitada, restringindo-se basicamente ao próprio meloeiro e as éspecies Cucurbita maxima e Cucurbita moschata.
\end{abstract}

Palavras-chaves: Cucumus melo; curcubitáceas; hortaliças.

Abstract: Grafting appears in the scenario of vegetable production as a strategy to escape adverse conditions from the continuous cultivation of these plants in the same area during practically the whole year. Choice of materials to be used as graft and rootstock allied to the type of grafting define the success of the technique in the production of commercial seedlings. Among the advantages provided by grafting are the possibility of increasing the resistance of plants to soilbourne pathogens, salinity, water deficit and also increases in productivity and fruit quality. For melons, the greatest bottleneck in the use of grafting is to obtain rootstocks that adapt to the environment, do not interfere negatively in the quality of the fruits and maintain resistance to diseases for a long period of time. The causes of incompatibility in the grafting of the melon aren't well clarified and incompatible answers may arise even after transplanting. The incentive to trace rootstock / graft combinations for melon is a potential means to overcome these limitations, since the range of commercial rootstocks is limited, being restricted basically to the melon itself and the Cucurbita maxima and Cucurbita Moschata.

Key-words: Cucumus melo; cucurbits; vegetables.

\section{INTRODUÇÃO}

A elevada procura de mercado por vegetais cultivados fora da época indicada, como o caso das curcubitáceas (melão, melancia, pepino e outras) aliada a limitações edafoclimáticas dos locais de cultivo faz com que estas espécies sejam cultivadas continuamente em condições desfavoráveis. Estas condições incluem ambientes muito frios, secos, excessivamente molhados, de baixa luminosidade durante a estação de cultivo, entre outras. Além disso, os efeitos da incidência de pragas e doenças, bem como o surgimento de plantas invasoras com alto poder de competição se atenuam à medida que a cultura principal sofre algum tipo de estresse durante seu crescimento. $\mathrm{O}$ impacto desses fatores, muita das vezes, pode 
resultar em distúrbios fisiológicos, levando as plantas cultivadas à redução na produtividade, qualidade do fruto produzido, bem como suscetibilidade ao ataque de agentes patogênicos, seje ele severo ou não.

A fumigação do solo, visando à eliminação de patógenos foi uma das práticas bastante utilizada para eliminação de patógenos nocivos as plantas, principalmente no cultivo de hortaliças. Todavia, o uso desta técnica além de eliminar patógenos causava redução dos micro-organismos antagonistas a estes, reduzindo a diversidade da fauna do solo. Outro agravante devia-se à persistência no solo por longo tempo do brometo de metila, principal produto usado para fumigação de solo (Aumonde et al., 2011). Por estas razões esta prática foi abolida do sistema de produção agrícola em acordo assinado na Convenção de Montreal de 1997.

No Brasil, todas as cultivares de melão, melancia e abóboras são suscetíveis a Meloidogyne spp. A espécie Cucumis metuliferus é altamente resistente a Meloidogyne bapla, M. incognita, $M$. javanica e $M$. arenaria, mas o cruzamento desta com Cucumis spp. visando a obtenção de híbridos resistentes, produtivos e com qualidade, não tem apresentado resultados satisfatórios (Pinheiro \& Amaro, 2010). A busca por estratégias de manejo que possibilitem as curcubitáceas resistir a esses problemas ainda é constante, em virtude da heterogeneidade das condições edafoclimáticas nos ambientes de cultivo no mundo (Davis et al., 2008)

A enxertia pode ajudar a superar alguns desses problemas. $\mathrm{O}$ uso de porta-enxertos oferece um dos melhores métodos para evitar doenças. Além disso, o enxerto pode afetar o crescimento vegetativo, floração, data e qualidade de amadurecimento dos frutos e rendimentos, especialmente sob condições de baixa temperatura (Davis et al., 2008). O objetivo desta revisão foi reunir informações a respeito do emprego da enxertia na cultura do meloeiro no cenário nacional e internacional.

\section{Importância e histórico da enxertia na horticultura mundial e no brasil}

O uso da enxertia na horticultura mundial visa, sobretudo, aumentar a resistência das mudas às doenças e em estudos mais recentes, incrementar a produtividade de frutos. É uma técnica empregada, prioritariamente para plantas das Famílias Solanaceae e Cucurbitaceae. Isso deve-se ao fato de que nem todas as espécies olerícolas apresentam características morfofisiológicas que possibilitam a enxertia. Entre as espécies de hortaliças, somente as das Famílias Solanaceae (tomate, pimentão e berinjela) e Cucurbitaceae (melancia, melão, pepino e abóbora) são comumente enxertadas comercialmente (Peil, 2003).

A técnica da enxertia foi utilizada pela primeira vez no Japão no final dos anos 20 , sendo realizada a enxertia de melancia (Citrullus lanatus Thunb.) em porta enxertos de abóbora (Cucurbita moschata Duchesne ex. Poir), no intuito de reduzir a infestação de doenças trasmitidas pelo solo (Jhoya, 1938). Na Europa, a enxertia de hortaliças é utilizada desde a década de 40, sendo iniciada pelos holandeses na cultura do tomate. No Brasil, o start da técnica deu-se a partir da década de 80 com os produtores de pepino objetivando 
melhorar a aparência do fruto e reduzir perdas ocasionadas por fungos de solo e nematóides (Peil, 2003).

Tipos de enxertia e benefícios da técnica para a propagação de hortaliças e do meloeiro

A enxertia tem sido utilizada para manejar patógenos de solo, doenças foliares, insetos e até mesmo plantas espontâneas (Louws et al., 2010). Além disso, plantas enxertadas mostram outras vantagens como melhoria da tolerância ao estresse abiótico, tolerância a solos salinos, hipoxia radicular, temperatura extremas, seca e inundação, aumento da eficiência do uso de nutrientes e água e, em alguns casos, ganhos em produtividade e melhoria de características qualitativas (Colla et al., 2010; Condurso et al., 2012).

No contexto nacional dentre as curcubitáceas comerciais as que mais se destacam quanto ao uso da enxertia são pepino e melancia. restrita a trabalhos de pesquisa, com poucos relatos de exploração comercial da cultura através de mudas enxertadas. Todavia, em países como Japão, Holanda e Espanha, onde a produção de hortaliças apresenta um caráter mais intensivo, esta técnica vem sendo adotada com grande ênfase pelos produtores de mudas de melão, sendo que no Japão cerca de aproximadamente $30 \%$ da área com melão é oriunda de mudas enxertadas (Dias \& Costa, 2010).

Dentre as modalidades de enxertia existentes, na horticultura mundial e em especial na cultura do meloeiro, têm sido utilizada com maior ênfase a perfuração com palito (combinação de palito com poda da raíz do portaenxerto), encostia, fenda cheia, corte em bisel do porta-enxerto e enxerto e combinação de poda da raíz do porta-enxerto com corte em bisel do porta-enxerto e enxerto (Figura 1) (Ito et al., 2008).

Para a cultura do melão esta técnica ainda está

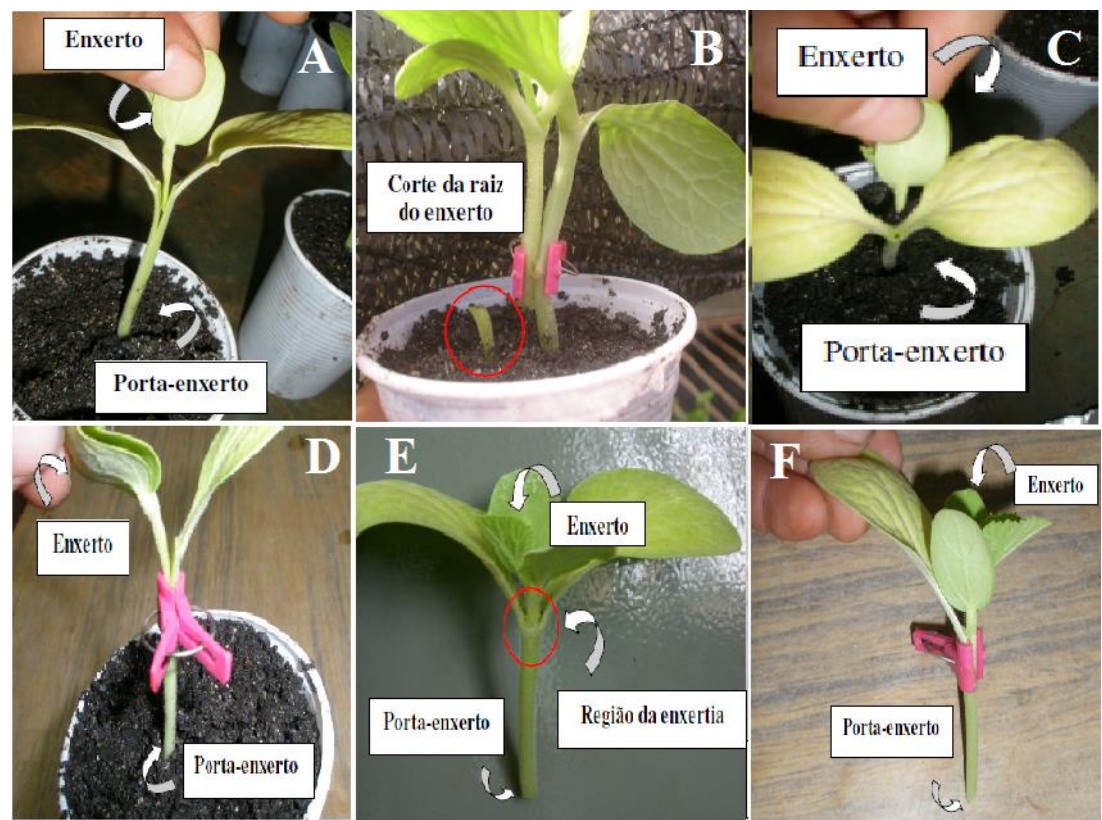

Figura 1. Enxertia do tipo fenda cheia (A), encostia (B), perfuração com palito no ápice do portaenxerto (C), em bisel (D), perfuração com palito no ápice do porta-enxerto sem raiz e inserção do enxerto (E) e do tipo Bisel utilizando a união do enxerto no porta-enxerto sem raiz em meloeiro (F). Adaptado de Ito (2009). 
As pesquisas com enxerto em melão iniciaram-se no Japão e os progressos da técnica para esta cultura foram lentos, uma vez que a maiora das cultivares de melões orientais (Cucumis melo L.) eram relativamente tolerantes às doenças do solo. Entretanto, com a crescente proliferação de fusarium em solos cultivados com melão no continente asiático a busca por metódos para suprimir os danos causados por este patógeno ganhou destaque (Jhoya, 1938). Este foi o marco inicial da enxertia em escala comercial em plantas de meloeiro. No Brasil, o uso da enxertia na cadeia produtiva do melão ainda é incipiente. Isso deve-se, principalmente, ao fato de os produtores considerarem a técnica muito complicada, uma vez que os benefícios da técnica bem como a existência de porta-enxerto resistentes são conhecidos (Ito, 2009).

(Colla et al., 2010) verificaram que a eficiência do uso do nitrogênio (EUN) e na absorção de $\mathrm{N}$ aplicado ao solo foi significativamente maior em $11,8 \%$ e $16,3 \%$, respectivamente, em plantas enxertadas sobre abóbora (Cucurbita maxima ou Cucurbita moschata) do que em plantas não enxertadas. Esses autores atribuíram essa resposta, principalmente, a um aumento da absorção de água e nutrientes resultante de um vigoroso sistema radicular do porta-enxerto, podendo ainda ter ocorrido aumento da produção endógena de hormônios. A ação conjunta de alguns ou de todos esses processos poderia explicar o maior rendimento em plantas enxertadas de melão em comparação as não enxertadas. Esses resultados demonstram que o cultivo de melão enxertado representa uma estratégia potencial para aumentar a EUN aplicado ao solo, bem como do rendimento de frutos, podendo contribuir para o fortalecimento da cadeia produtiva do melão em solos com baixo estoque de $\mathrm{N}$, que demandam altos níveis de aplicações deste elemento, como é o caso de solos do nordeste brasileiro.

Meloeiros enxertados em porta-enxertos de C. maxima e C. moschata apresentaram maior concentração de nitrato na seiva do xilema do que na raiz da planta (Salehi et al., 2010). Além disso, menores concentrações foliares de nitrato em meloeiros e melancias enxertadas foram acompanhadas por maiores atividades de nitrato redutase em comparação com plantas autoenxertadas, o que sugere um elevado nível de assimilação de nitrogênio em plantas enxertadas (Pulgar et al., 2000).

Além disso, a enxertia pode atuar na expressão gênica da planta, aumentando a produção de proteínas relacionadas à fotossíntese, metabólitos de defesa e ativação de genes funcionais (Guan et al., 2012).

\section{Limitações da técnica de enxertia e seus reflexos para a cultura do melão}

Entre os fatores que podem determinar o sucesso da enxertia destacam-se: metodologia empregada, idade do enxerto e porta-enxerto, compostos presentes nos tecidos das estruturas enxertadas e condições ambientais do local de cultivo. O enxerto bem sucedido é um processo complexo que começa com adesão dos dois parceiros enxertados, seguida da formação de 
calos e o estabelecimento de um sistema vascular funcional (Cookson et al., 2014).

(Cookson et al., 2013) relatam que em videira o desenvolvimento da união do enxerto e do porta-enxerto envolve a regulação positiva de muitos genes envolvidos na síntese da parede celular, respostas à ferida, metabolismo secundário e sinalização. Em videira o uso de hetero-enxertos mostrou que a base genética das estruturas de união "enxerto e porta-enxerto", dentro da mesma espécie, pode atenuar a incompatibilidade da enxertia. Isso ocorre devido ao desencadeiamento da expressão de numerosos genes na interface da região enxertada logo no primeiro mês após a enxertia, fazendo com que o porta-enxerto expresse resposta do tipo imunológica aos genes oriundos do enxerto (Cookson et al., 2014). Devido a essa complexidade, as causas de incompatibilidade do enxerto com porta-enxerto são desconhecidas e respostas incompatíveis podem surgir muitos anos após a execução da técnica. O maior gargalo no emprego da enxertia é a obtenção de bons porta-enxertos, que se adaptem ao meio ambiente, não interfiram negativamente na qualidade dos frutos e mantenham a resistência às doenças por longo período de tempo (Gaion, 2013).

\section{Escolha do porta-enxerto e do enxerto}

No Brasil trabalhos que direcionem a escolha do porta-enxerto e do enxerto a ser utilizado na cultura do meloeiro ainda são incipientes. A maioria dos que estão disponíveis na literatura têm enfoque em seleção para resistência a doenças, e em especial, objetivam incrementos em produtividade. A finalidade para qual a técnica será empregada é sem dúvida a diretriz básica de seleção tanto do porta-enxerto como do material a ser enxertado. Nestes estudos a compatibilidade entre as parte comunicantes é parâmetro crucial para o avanço no emprego da técnica, visto que determinará a obtenção de plantas ativas, capazes de responderem e interagirem com os fatores do meio.

Nessa perspectiva Galatti et al., (2013) usando enxertia do tipo garfagem por fenda simples, verificaram que dentro da própria espécie Cucumus melo ocorrem materiais "cultivares" (Redondo amarelo $\mathrm{x}$ Rendilhado) com alto percentual de compatibilidade (100\%). Estes autores constataram ainda que o \% de pegamento, ou seja, de compatibilidade, decresce com o ampliamento da base genética, sendo observado 66, 62 e 50\% de compatibilidade na enxertia do melão rendilhado sobre porta-enxertos de bucha, melancia e Abóbora 'Goianinha', respectivamente. Já Rizzo et al. (2004) obtiveram maiores \% de pegamento, diâmetro médio longitudinal dos frutos e maiores quantidades de sólidos solúveis totais quando utilizada enxertia do tipo fenda cheia. Enquanto Ito et al. (2008) utilizando como enxerto de meloeiro a cultivar 'Bônus $\mathrm{n}^{\circ}{ }^{2}$ ' no porta-enxerto ('Shelper') não observaram melhoria da técnica da enxertia na produção e qualidade de frutos, sendo que as enxertias do tipo Fenda Cheia e Bisel sem raíz promoveram menores valores para os atributos de qualidade do fruto analisados.

Estes resultados enfatizam a importância da ampliação de estudos dentro da própria técnica da enxertia, como tempo de execução entre corte e junção das partes comunicantes, idade dos 
tecidos, bem como o próprio tipo de enxertia empregado, pois, a busca por ampliação da base genética é primordial para obtenção de resistência a patógenos e elevação da heterose, podendo incrementar a produtividade.

\section{Resistência a doenças, qualidade e produtividade de frutos e tempo de produção}

Embora seja conhecido que a técnica da enxertia altera os atributos de rendimento $\mathrm{e}$ qualidade dos frutos, a indústria hortícola tem tradicionalmente focado apenas em incrementos de produtividade (Condurso et al., 2012). No que diz respeito às podridões, enfoque tem sido dado na seleção de porta-enxerto resistente ao agente fúngico Fusarium solani (Gaion, 2013). Além de comprometer o desenvolvimento radicular com posterior tombamento de plântulas há relatos da associação deste fitopatógeno com a ocorrência do colapso do meloeiro, um complexo de doença onde há associação de diversos patógenos habitantes do solo como, F. solani, Macrophomina phaseolina, Monosporascus cannonballus, Rhizoctonia solani e Sclerotium rolfsii (Garcia-Jiménez et al., 2000; Andrade et al., 2005).

Em pepinos enxertados em C. Moschata o enxerto aumentou a população de bactérias e actinomicetos enquanto o número total de fungos na rizosfera foi reduzido (Dong et al., 2010). Jiang et al. (2010) trabalhando com pimentas enxertadas e inoculadas com $F$. solani verificaram que populações de actinomicetos na rizosfera foram maiores quando empregou-se porta-enxerto resistente e plantas enxertadas sobre estes, em comparação a plantas controle (auto-enxertadas). Isso remonta o benefício que a enxertia traz para o sistema de produção, alterando a microbiota do solo pela exsudação de compostos produzidos por plantas enxertadas que exerçam ação antagônica aos organismos do solo.

$\mathrm{Na}$ Itália, por exemplo, a utilização de porta-enxertos híbridos resistentes representa o principal instrumento de prevenção de doenças na cultura do meloeiro (Martignoni et al., 2011). Nesse sentido, o emprego de porta-enxertos pertencentes a espécies diferentes é preferível, devido a diversidade genética (Ito et al., 2014). A utilização da cucurbitácea C. metuliferus como porta-enxerto para o melão tem demonstrado eficiência na prevenção do crescimento da população de M. incognita (Sigüenza et al., 2005).

Condurso et al. (2012) detectaram que o uso da enxertia em meloeiro favorece a redução do ciclo, permite aumentar a produtividade em $60 \%$ da apresentada por plantas não enxertadas, além de promover maior número de frutos por planta. Ainda neste mesmo estudo foi observado que a enxertia de meloeiro sobre outras espécies de curcubitáceas resulta em menores teores de ésteres, responsáveis pelo aroma característico do fruto. Entretanto o uso de porta-enxertos híbridos de abóbora melhorou a qualidade dos frutos, aumentado em cerca de oito vezes a quantidade de carotenóides $(56 \%$ a mais que plantas não enxertadas), comportamento não verificado quando a enxertia foi realizada em porta-enxertos de meloriro.

A divergência ns parâmetros de qualidade em razão do tipo de porta-enxerto empregado evidencia a importância do rastreamento para as combinações de porta-enxerto/enxerto, quando o foco está em incrementos na qualidade do fruto, 
especialmente aroma, sabor e para o sucesso contínuo da enxertia.

\section{CONSIDERAÇÕES FINAIS}

O successo da enxertia no meloeiro requer o contato proximal entre os feixes vasculares do enxerto e porta-enxerto, compatibilidade com porta-enxertos de outras espécies e condições ambientais que favoreçam a união das partes combinantes. As plantas enxertadas com uma boa combinação apresentam, na maioria das vezes, resistência a doenças, melhor tolerância ao estresse abiótico e maior produção de frutos. Infelizmente, a gama de porta-enxertos comerciais é limitada, e o efeito de porta-enxertos inexplorados sobre a qualidade ainda não está claro.

\section{REFERÊNCIAS BIBLIOGRÁFICAS}

ANDRADE, D. E. G. T.; MICHEREFF, S. J.; BIONDI, C. M.; NASCIMENTO, C. W. A.; SALES JUNIOR, R. Freqüência de fungos associados ao colapso do meloeiro e relação com características físicas, químicas e microbiológicas dos solos. Summa Phytopathologica, Botucatu, v.31, n. 4, p.327-333, 2005.

AUMONDE, T. Z.; LOPES, N. F.; PEIL, R. M. N.; MORAES, D. M.; PEDÓ, T.; PRESTES, S. L. C.; NORA, L. Enxertia, produção e qualidade de frutos do híbrido de mini melancia smile. Revista Brasileira de Agrociência, Pelotas, v. 17, n. 1-4, p. 42-50, 2011.

COLLA, G.; SUÁREZ, M. C. C.; CARDARELLI, M. Improving Nitrogen Use
Efficiency in Melon by Grafting. Hortscience, Alexandria, v. 45, n. 4, p. 559-565, 2010.

CONDURSO, C.; VERZERA, A.; DIMA, G.; TRIPODI, G.; CRINÒ, P.; PARATORE, A.; ROMANO, D. Effects of different rootstocks on aroma volatile compounds and carotenoid content of melon fruits. Scientia Horticulturae, Amsterdam, v. 148, p. 9-16, 2012.

COOKSON, S. J. et al. Graft union formation in grapevine induces transcriptional changes related to cell wall modification, wounding, hormone signalling, and secondary metabolism. Journal of Experimental Botany, Oxford, v. 64, n. 10, p. 2997-3008, 2013

COOKSON, S. J.; MORENO, M. J. C.; HEVIN, C.; MENDOME, L. Z. N.; DELROT, S.; MAGNIN, N. Heterografting with nonself rootstocks induces genes involved in stress responses at the graft interface when compared with autografted controls. Journal of Experimental Botany, Oxford, v. 65, n. 9, p. 2473-2481, 2014.

DAvIS, A. R. et al. Cucurbit Grafting, Critical Reviews in Plant Sciences. Taylor \& Francis, v. 27, n. 1, p. $50-74,2008$.

DIAS, R. C. S.; COSTA, N. D. Sistema de produção de melão: propagação. Embrapa Semiárido: Sistemas de Produção, n. 5. 2010. Disponível em: http://www.cpatsa.embrapa.br:8080/sistema_ producao/spmelao/producao_de_mudas.html. Acesso em: 18 de Mar. 2017.

DONG, L.; ZUO, Y.; LI, X.; WANG, Q. Effects of grafting on cucumber soil biochemistry. 
Journal of China Agricultural University, v. 15, n. 4, p. 51-56, 2010.

GAION, L. A. Enxertia e podridão de raízes e colo em curcubitáceas. 2013. 67f. Dissertação (Mestrado em Agronomia)Universidade Estadual Paulista "Júlio de Mesquita Filho" (UNESP), Jaboticabal, 2013.

GALATTI, F. D. S.; FRANCO, A. J.; ITO, L. A.; CHARLO, H. D. O.; GAION, L. A.; BRAZ, L. T. Rootstocks resistant to Meloidogyne incognita and compatibility of grafting in net melon. Revista Ceres, Viçosa, v. 60, n. 3, p. 432-436, 2013.

GARCIA-JIMÉNEZ， J.; ARMENGOL， J.; SALES JÚNIOR, R.; JORDÁ, C.; BRUTON, B.D. Fungal pathogens associated with melon plants collapse in Spain. EPPO Bulletin, Paris, v. 30, n. 2, p.169-173, 2000.

GUAN, W.; ZHAO, X.; HASSELL, R.; THIES, J. Defense Mechanisms Involved in Disease Resistance of Grafted Vegetables. Hortscience, Alexandria, v. 47, n. 2, p. 164 170, 2012.

ITO, A. Métodos de enxertia em melão rendilhado e seus efeitos na produtividade em três épocas de cultivo. 2009. 60f. Dissertação (Mestrado em Agronomia)Universidade Estadual Paulista "Júlio de Mesquita Filho" (UNESP), Jaboticabal, 2009.

ITO, L. A.; CARDOSO, A. F.; BRAZ, L. T. Produtividade de melão rendilhado "Bônus $\mathrm{n}^{\circ} 2$ ", em função da modalidade de enxertia. Horticultura Brasileira, v. 26, n. 2, p. 40494053, 2008.

ITO, L. A.; GAION, L. A.; GALATTI, F. S.; BRAZ, L. T.; SANTOS, J. M. Resistência de porta-enxertos de cucurbitáceas a nematóides e compatibilidade da enxertia em melão. Horticultura Brasileira, Brasília, v. 32, n. 3, p. 297-302, 2014.

JHOYA, Y. Fusarium wilt of cucurbits. Journal Plant Protection, v. 25, n. 1, p. 215-220, 293296, 1938.

JIANG, F.; LIU Y. X.; AI, X. Z.; ZHEN, N.; WANG, H.T. Study on relationship among microorganism, enzymes' activity in rhizosphere soil and root rot resistance of grafted capsicum. Scientia Agricultura Sinica, v. 43, p. 3367-3374, 2010.

LOUWS, F. J.; RIVARD, C. L.; KUBOTA, C. Grafting fruiting vegetables to manage soilborne pathogens, foliar pathogens, arthropods and weeds. Scientia Horticulturae, Amsterdam, v. 127, n. 2, p. 127-146, 2010.

MARTIGNONI, D.; REDA, R.; ALEANDRI, M. P.; CHILOSI, G. Evaluation of response of a melon rootstock to mycorrhization with the AM Glomus intraradices in nursery. In: INTERNATIONAL SYMPOSIUM ON VEGETABLE GRAFTING, 2011, Viterbo. Abstracts... Viterbo: [Universitá Degli Studi della Tuscia], 2011. p. 77.

PEIL, R. . A enxertia na produção de mudas de hortaliças Grafting of vegetable crops. Ciência Rural, Santa Maria, v. 33, n. 6, p. 1169-1177, 2003.

PINHEIRO, J. B; AMARO, G. B.. Ocorrência e controle de nematoides nas principais espécies cultivadas de cucurbitáceas. Embrapa Hortaliças. Circular técnica. 2010. 7p.

PULGAR, G.; VILLORA, G.; MORENO, D.; 
ROMERO, L. Improving the mineral nutrition in grafted watermelon plants: nitrogen metabolism. Biologia Plantarum, Praha, v. 43, n. 4, p. 607-609, 2000.

RIZZO, A. A. N.; CHAVES, F. C. M.; LAURA, V. A.; GOTO, R. Avaliação de métodos de enxertia e porta-enxertos para melão rendilhado. Horticultura Brasileira, Brasília, v. 22, n. 4, p. 808-810, 2004.

SALEHI, R.; KASHI, A.; LEE, J.; DELSHAD, M.; BABALAR, M.; HUH, Y.; LEE, S. Leaf
Gas Exchanges and Mineral Ion Composition in Xylem Sap of Iranian Melon Affected by Rootstocks and Training Methods. Hortscience, Alexandria, v. 45, n. 5, p. 766770, 2010.

SIGÜENZA, C.; SCHOCHOW, M.; TURINI, T.; PLOEG, A. Use of Cucumis metuliferus as a Rootstock for Melon to Manage Meloidogyne incognita. Journal of Nematotology, v. 37, n. 3, p. 276-280, 2005. 